\title{
Preliminary Study on Mitochondrial DNA Cytochrome $B$ Sequences and Genetic Relationship of Three Asian Arowana Scleropages Formosus
}

\author{
Yinchang $\mathrm{Hu}$ \\ Pearl River Fisheries Research Institute, Chinese Fishery Academy of Sciences \\ Xilang, Fangcun district, Guangzhou 510380, China \\ Tel: 86-20-8161-6088 E-mail: huyc2@163.com
}

Xidong $\mathrm{Mu}$

Pearl River Fisheries Research Institute, Chinese Fishery Academy of Sciences

Xilang, Fangcun district, Guangzhou 510380, China

Tel: 86-20-2217-5232 E-mail: muxd1019@126.com

Xuejie Wang

Guangzhou tiny-lake aquatic organism technology co., ltd

Xilang, Fangcun district, Guangzhou 510380, China

Tel: 86-20-81617952Ｅ-mail: aqwang@163.com

Chao Liu

Guang zhou tiny-lake aquatic organism technology co., ltd

Xilang, Fangcun district, Guangzhou 510380, China

Tel: 86-20-81617952 E-mail: truman.liu@tom.com

\section{Peixin Wang}

Pearl River Fisheries Research Institute, Chinese Fishery Academy of Sciences

Xilang, Fangcun district, Guangzhou 510380, China

Tel: 86-20-8161-6127Ｅ-mail: wpx@126.com

Jianren Luo

Pearl River Fisheries Research Institute, Chinese Fishery Academy of Sciences

Xilang, Fangcun district, Guangzhou, 510380, China

Tel: 86-20-8161-6133Ｅ-mail: fishlo@163.net

The research is financed by The People's Republic of China Ministry of Agriculture Affairs State(948), Science Research Institute fund of scientific research operational fee technical Program from Chinese Academy of Fishery Sciences Research InstituteNo. 2130108, Technology fund of Pearl River Fisheries Research InstituteNo.2003-3-5, Science and Technology Developing Fisheries Program of liwan district Guangdong Province. No. 20082109029 


\begin{abstract}
Mitochondrial DNA cytochrome $b$ (cytb) gene complete sequences of golden arowana, red arowana and green arowana of Scleropages formosus were amplified with PCR technique and sequenced.The sequence length was $1141 \mathrm{bp}$ for three Asian arowanas which had 5 nucleotide sites substituted, among of them 4 base substitutions were transition and only 1 was transversion, all of the base substitution happened in the third locus of the codon which only 1 site caused amino acid variation. A global deficit of guanosines (G:13.7\%) and approximately equal frequencies of the other three nucleotides (A: $27.8 \%$, C: $34.6 \%$, T: $23.9 \%$ ) and $\mathrm{G}+\mathrm{C}$ content $(48.3 \%)$ was quite constant among sequences. The genetic distance of mtDNA cyt $b$ gene sequences was 0.0026-0.0035 between green arowana and the other two Asian arowana, which indicated that Asian arowana perhaps did not evolve to the level of specie. Phylogenetic trees were constructed with NJ method and MP method using arithmetic average method.The results showed that red arowana clustered with golden arowana, after clustering with green arowana.
\end{abstract}

Keywords: Scleropages formosus, Cytochromeb, Genetic relationship

\title{
1. Introduction
}

Asian arowana (Scleropages formosus) is known as dragonfish, Asia Bonytongue, kelisa or bajurantai. There are considered "lucky" by many people, particularly those from Asian cultures. Due to its popularity and great demand, Asian arowanas have been fiercely hunted in its native habitat for profits, causing declination of the population of these fishes in the wild. Arowanas have been classified as an endangered species, threatened with extinction in CITES appendix I since 1980(Joseph, 1986, p73) and have listed as endangered by the 2006 IUCN Red List (Kottelat, 1996). There are a number of breeders registered CITES in Asia so that the specimens what they produce can be imported into several nations. Other nations restrict or prohibit possession of Asian arowanas. The Asian arowana consists of geographically isolated strains distributed in Southeast Asia. The green, gold strains of Asian arowana have lower commercial value than the red one (Kottelat, 1993). More work is needed to understand genetic relationship in arowanas.

Mitochondrial DNA analysis has become a widely used technique for many applications in population or evolutionary studies(Avise, 1986, p1192; Fumihitoetal, 1995, p11053; Randietal, 2000. p1103).The cytochrome $b$ gene (cyt $b$ ) from mitochondrial genome contains species-specific information and has been used in phylogeny (Irwin, 1991, p128).In the study, mtDNA cytb sequences of three Asian arowana were obtained and compared with each other for further clarifying phylogenetic relationship among Asian arowanas, with a view to raise awareness of resources.

\section{Material and methods}

\subsection{Samples and DNA isolation}

Fin clips of three Asican arowanas samples from Guang zhou tiny-lake aquatic organism technology co., ltd housed which were originated from Malaysia collected in 2001, were collected, and kept in absolute ethanol. Genomic DNA was extracted from Fin clip of each fish using a Blood \& Cell Culture DNA Kit (Tiangen, Beijing, China).

\subsection{PCR protocol}

PCR was performed in a final volume of $20 \mu$ l using a Cycler machine.The reaction mix contained $10 \times$ PCR buffer $2.0 \mu l$, $\mathrm{MgCl}_{2} \quad(25 \mathrm{mmol} / \mathrm{L}) \quad 1.6 \mu \mathrm{l}$, dNTPs $(10 \mathrm{mmol} / \mathrm{L}$ each $) 0.4 \mu \mathrm{l}$, each primer $(20 \mu \mathrm{mol} / \mathrm{L}) \quad 0.5 \mu \mathrm{l}, \quad$ Taq DNApolymerase $(5 \mathrm{U} / \mathrm{Ml}) 0.3 \mathrm{U}$, and DNA template 50ng. The primers used for the amplification were cytb1 (5'-TGCGACTAAACATAAATGTTTAG-3') and cytb2 (5`-TGTATGGAAA TTGCAGTTATG-3').Amplification was carried out using $2 \mathrm{~min}$ of initial denaturation followed by 30 cycles of $50 \mathrm{~s}$ of denaturation at $94^{\circ} \mathrm{C}$, 50s annealing at $52^{\circ} \mathrm{C}$ and $60 \mathrm{~s}$ extension at $72^{\circ} \mathrm{C}$ with a final extension period of $5 \mathrm{~min}$ at $72^{\circ} \mathrm{C}$.After the electrophoretic run, DNA molecules were visualized under UV light and analyzed.The amplified products were sequenced directly with an ABI DNA Sequencer. Sequencing reactions were carried out as recommended by the manufacturer.

\subsection{Sequences and alignment}

DNA sequences were initially automatically aligned using Clustal X vers. 1.8 (Thompson, 1997, p4876), followed by manual editing. Phylogenetic analysis of the aligned sequences was performed with the Molecular Evolutionary Genetics Analysis (MEGA) programvers. 3.0 (Kumar, 2001). Distance analysis was conducted using the Neighbor-joining (NJ) option employing the p-distance with gap data treated as pairwise deletions. MP analysis was conducted using heuristic searches, 1000 bootstrap replicates, and 100 randomly added trees of sequences to search for the most parsimonious trees.

\section{Results}

\subsection{Sequence characteristics and variation}

$1141 \mathrm{bp}$ length for the entire cytb were sequenced for three Asian arowana(Figure1).All sequences were submitted to GenBank (accession to GenBank:Gold Arowana, EU594546, Red Arowana EU594545, Green Arowana EU594547). 
Base composition in three sequences was similar to that of previously reported fish cytochrome $b$ sequences (Rafael, 1998, p1365; Jerome, 1998, p100; Johanna, 2007, p43): low G content (mean: 13.7\%) and almost equal A, C, and T contents (mean: $27.8,34.6$, and $23.9 \%$, respectively). This pattern was mainly due to third codon positions (mean G content at third codon positions: $4.1 \%$ ) and to a lesser extent to second codon positions (mean G content at second codon positions: $13.2 \%$ ), whereas base composition in first codon positions was balanced (mean T, C, A, and G contents at first codon positions: $22.3,27.6,26.4$, and $23.7 \%$, respectively) (Table1.). Base composition was quite homogeneous among sequences: $\mathrm{G}+\mathrm{C}$ content $48.3 \%$.

Among 1141 nucleotide sites, 5 nucleotide sites substituted, among of them 4 base substitutions were transition and only one was transfusion, all of the base substitution happened in the third locus of the codon which only 1 site caused amino acid variation, suggesting that these sites may be prone to saturation.

\subsection{Phylogenetic Relationships}

Genetic distances within and between stocks based on cytb are shown in Table 2.For cytb, the results indicate that genetic distances within populations were below $0.1 \%$.Based on the cyt $b$ sequences, the MP and NJ trees of three Asian arowanas were constructed. The MP and NJ tree had the same (Figure2). The results showed that these two methods were effective in common laboratories.

\section{Discussion}

$1141 \mathrm{bp}$ length for the entire cytb genes were sequenced of three Asian arowana, containing the start codon ATG, with T for the stop codon which is not a complete stop codon in the transcription process to be added after the formation of polyA stop codon. This study showed that genetic distance among three Asian arowanas between $0.26 \% \sim 0.35 \%$. Billington (1991, p80) reported intraspecific divergence at the $10 \%$ of the general level. Nei $(1990, \mathrm{p} 873)$ that the same individuals are generally $0.1 \%$ to $5 \%$ of the divergence. According to both differences in the degree of cytb gene, the study concluded that three Asian arowanas differentiation between the subspecies may have already reached the level Consistent with the morphological.

Since Muller first found and named in 1933, the taxonomic classification of Scleropages formosus has undergone not any changes. Scleropages formosus refers to several varieties of freshwater fish in the genus. The present study demonstrates that the classification of subspecies is consistent with the genetic clusters in Scleropages formosus. Geological evidence showed that continental Southeast Asian terranes could be classified into two categories, based on their Late Palaezoic tectonic history (Hutchison, 1993, p883). It is believed that different strains of arowana inhabit separate regions of Southeast Asia and were connected through freshwater habitats during the Pleistocene era (Goh, 1999), implying that freshwater fishes could not have migrated between the two supercontinents after 160 MYA. The fossil records of Scleropages which should be considered in evaluating the migrational history of the Asian arowana. Freshwater beds of Eocene times (35-57 MYA) in central Sumatra yielded fossils that could be attributed to the genus Scleropages. The Indian subcontinent became connected to Eurasia by the late Early Eocene (Jaeger, 1989, p316; Metcalfe, 1999, p9) implying an ancestor of the Asian arowana originated when Laurasia and Gondwanaland were still connected and that it dispersed via fresh water habitats from Gondwanaland to Laurasia. The morphological similarity of all Scleropages species shows that little evolutionary change has taken place recently for these ancient fish(Kumazawa, 2000, p1869). The morphological similarity of all Scleropages species shows that little evolutionary change has taken place recently for these ancient fish. Genetic studies also have confirmed these.Yue (2000, p1007; $2000, \mathrm{p} 89 ; 2002$, p1025; 2003, p951;2006, p627) successfully examined genetic diversity and population structure of Scleropages formosus originating from the south-east Asian regionusing RAPD and AFLP, and reported the identification of a sex-associated AFLP marker and a strain-specific RAPD marker in the Asian arowana using pooled DNA samples. The two markers were successfully converted into STS markers and are applicable for rapid sexing of the green strain or for differentiation of the Indonesian golden strain from blood red and green varieties respectively. Tang $(2004, \mathrm{p} 81)$ supported the view that green arowana is the outgroup among the arowana strains using microsatellite and mtDNA. At the same time, the results showed the correlation between molecular marker diversity and geographic region that several of arowana strains diverged from late Pliocene to middle Pleistocene. The isolated strains evolved at intraspecific level. As noted above, genetic estimates of divergences suggest an early divergence between Asian arowanas taxa occurred from the late Pliocene to middle Pleistocene. However, it should also be greater use of molecular markers, such as D-loop, COI to verify this inference, etc.

\section{References}

Avise, J.C. (1989). Gene trees and organismal histories: a phylogenetic approach to population biology. Evolution, 43: 1192-1208.

Billington N, \& Hebert PDN. (1991). Mitochondrail DNA diversity in fishes and its implications for introductions. Can J Fish Aquat Sci, 48(sup.): 80-94.

Dawes J, Lim LL, Cheong L. (1999). The Dragon Fish. Kingdom Books England. 
Fumihito A, Miyake T, \& Sumi SI. (1995). The genetic link between the Chinese bamboo partridg(Bambusicola thoracica) and the chicken and junglefowls of the genus Gallus.Proceedings of the National Academy of Science of the United States of America, 92(24):11053-11056.

Goh, W., \& Chua, J. (1994). The Asian arowana. Dragon FishIndustry. Singapore: E-Publishing Inc. pp.17-24

Hutchison, C.S. (1993). Gondwana and Cathaysian blocks, Palaeotethys sutures and Cenozoic tectonics in Southeast Asia. Geologische Rundschau, 82: 388-405.

Irwin DM, KocherTD, \&WilsonAC. (1991). Evolution of cytochromeb gene of mammals. J Mol Evol, 32:128-14

Jerome B, Nicolas G, \& Miguel B. (1998). Molecular Phylogeny of Cyprinidae inferred from cytochrome b DNA Sequences. Molecular phylogenetics and evolution, 9(1): 100-108

Johanna J, ChristoV, \&Jon-Arne S. (2007). Four genes, morphology and ecology: distinguishing a new species of Acesta (Mollusca; Bivalvia) from the Gulf of Mexico. Mar Biol, 152:43-55.

Joseph J, Evans D, \&Broad S. (1986). International trade in Asian Bonytongues. Traffic Bulletin, 3, 73-76.

Kottelat M, Whitten AJ, \& Kartikasari SN. (1993).Freshwater Fishes of Western Indonesia and Sulawesi. Periplus Editions (HK) Ltd, Indonesia.

Kottelat, M.(1996). Scleropages formosus. (2006). IUCN Red List of Threatened Species. IUCN 2006.

Kumar S, Tamura K, \&Nei M. (2001). MEGA (Molecular evolutionary genetics analysis), Version 3.0. Tempe: Arizona State University.

Kumazawa Y, \&Mutsumi N. (2000). Molecular Phylogeny of Osteoglossoids: A New Model for Gondwanian Origin and Plate Tectonic Transportation of the Asian Arowana. Mol.Biol.Evol, 17(12): 1869-1878

Jaeger, jj., v. courtillot, \& p. tapponnier. (1989). Paleontological view of the ages of the Deccan Traps, the Cretaceous/Tertiary boundary, and the India-Asia collision. Geology, 17:316-319.

Metcalfe, I. (1999). Gondwana dispersion and Asian accretion: an overview. Pp. 9-28.

Nei M, \& Miller JC. (1990).A simple method for estimating average number of nucleotide substitution within and between populations from restriction data. Genetics, 125:873-879.

Randi V, Lucchini T, \& Armijo P. (2000). MitochondrialDNA phylogeny and speciation in the Tragopans.Auk, 117(4):1003-1015.

Rafael Z, \&Ignacio D. (1998). Phylogenetic relationships of Iberian cyprinids: systematic and biogeo -graphical implications. Proc. R. Soc. Lond. B, 265:1365-1372.

Tang PY, \&Sivananthan J. (2004). Pillay SO, et al.Genetic Structure and Biogeography of Asian Arowana (Scleropages formosus) Determined by Microsatellite and Mitochondrial DNA analysis. Asian Fisheries Science, 17:81-92.

Thompson J D, Gibson T J, \&Plewnia F. (1997). The Clustal_X windows interface: Flexible strategies ed for multiple sequences alignment aided by quality analysis tools. Nuc Aci Res, 25: 4876-4882.

Yue GH, Li Y, \& Chen F. (2002). Comparison of three DNA markers systems for assessing genetic diversity in Asian arowana.Electrophoresis, 23:1025-1032.

Yue GH, Chen F \& Orban L. (2000). Rapid isolation and characterization of microsatellites from the genome of Asian arowana (Scleropages formosus, Osteoglossidae, Pisces). Mol Ecol, 9:1007-1009.

Yue, G.H., Li, Y., \& Chen, F. (2000). Monitoring the genetic diversity of three Asian arowana (Scleropages formosus) stocks using AFLP and microsatellites. Aquaculture, 237, 89-102

Yue, G.H, Ong, D, \&Wong, CC. (2003). A strain-specific and a sex-associated STS marker for Asian arowana (Scleropages formosus, Osteoglossidae). Aquaculture Research, 34 (11): 951-957.

Yue, G.H., Zhu, Z.Y., \& Lin, L.C. (2006).Novel polymorphic microsatellites for studying genetic diversity of red Asian Arowanas. Conservation Genetics, 7, 627-629.

\section{Notes}

Note 1 . This is an example.

Note 2. This is an example for note 2

Note 3. This is an example for note 3 
Table 1. Nucleotide composition for cytochrome $b$ gene sequences(1141bp) of Asian arowana

\begin{tabular}{|c|c|c|c|c|c|c|}
\hline Nucleotide composition & $\mathrm{T}(\%)$ & $\mathrm{C}(\%)$ & $\mathrm{A}(\%)$ & $\mathrm{G}(\%)$ & $\mathrm{A}+\mathrm{T}(\%)$ & $\mathrm{G}+\mathrm{C}(\%)$ \\
\hline Green arowana & 23.9 & 34.6 & 27.8 & 13.7 & 51.7 & 48.3 \\
\hline Red arowana & 24.0 & 34.5 & 27.8 & 13.7 & 51.8 & 48.2 \\
\hline Gold arowana & 23.9 & 34.6 & 27.8 & 13.7 & 51.7 & 48.3 \\
\hline Average & 24.0 & 34.6 & 27.8 & 13.7 & 51.8 & 48.2 \\
\hline
\end{tabular}

Table 2. Genetic distance among three Asian arowanas

\begin{tabular}{|l|l|l|l|}
\hline & Red arowana & Green arowana & Gold arowana \\
\hline Red arowana & - & & \\
\hline Green arowana & 0.0026 & - & \\
\hline Gold arowana & 0.0026 & 0.0035 & - \\
\hline
\end{tabular}

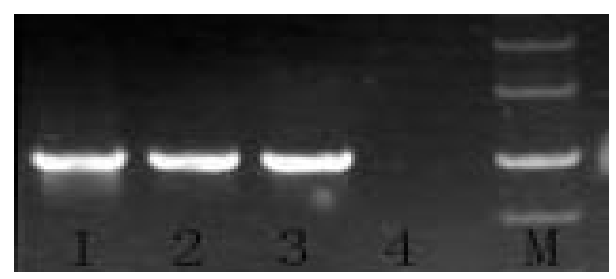

Figure 1. Agrose gel electrophoresis of Cyt $b$ gene PCR products

1: Green Arowana; 2: Gold Arowana; 3: Red Arowana; 4: Blank; M:marker

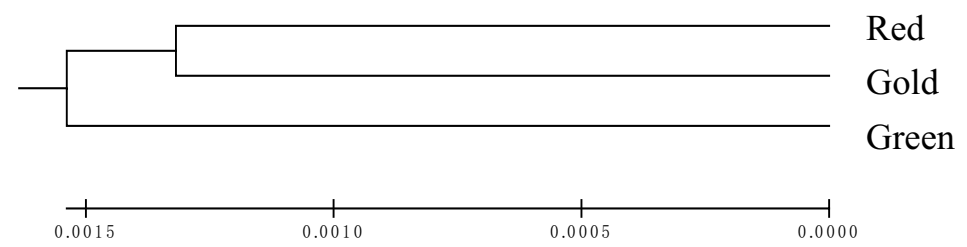

a.

Red

Green

Gold

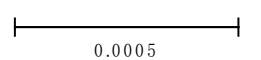

b.

Figure 2. Phylogenetic trees of the three Asian arowanas based on the cyt $b$ sequences a. MP b. NJ trees 